\title{
Digital participation? Internet use among adolescents with and without intellectual disabilities: A comparative study
}

Kristin Alfredsson Ågren, Anette Kjellberg and Helena Hemmingsson

The self-archived postprint version of this journal article is available at Linköping University Institutional Repository (DiVA):

http://urn.kb.se/resolve?urn=urn:nbn:se:liu:diva-162754

N.B.: When citing this work, cite the original publication.

Alfredsson Ågren, K., Kjellberg, A., Hemmingsson, H., (2019), Digital participation? Internet use among adolescents with and without intellectual disabilities: A comparative study, New Media and Society, , UNSP 1461444819888398. https://doi.org/10.1177/1461444819888398

Original publication available at:

https://doi.org/10.1177/1461444819888398

Copyright: SAGE Publications (UK and US)

http://www.uk.sagepub.com/home.nav 


\title{
Digital participation? Internet use among adolescents with and without intellectual disabilities: A comparative study
}

Kristin Alfredsson Ågren ${ }^{\mathrm{a}}$, Anette Kjellberg ${ }^{\mathrm{a}}$, Helena Hemmingsson ${ }^{\mathrm{a}, \mathrm{b}}$

${ }^{\text {a }}$ Division of Occupational Therapy, Department of Social and Welfare Studies, Faculty of Health Sciences, Linköping University, Norrköping, Sweden

${ }^{\mathrm{b}}$ Department of Special Education, Stockholm University, 10691 Stockholm, Sweden Corresponding author:

Kristin Alfredsson Ågren, Msc OT, Reg OT, PhD-student kristin.alfredsson.agren@liu.se

\begin{abstract}
Internet use is an integrated part of everyday life, especially among young people. However, knowledge of this for young people with disabilities is scarce. This study investigates digital participation of adolescents with intellectual disabilities by comparing aspects of internet use among adolescents with and without intellectual disabilities. Cross-sectional comparative design was used and a national survey from the Swedish Media Council was cognitively adapted for adolescents with intellectual disabilities aged 13-20 years. The results reveal that a significantly lower proportion of the 114 participating adolescents with intellectual disabilities had access to internet-enabled devices and performed internet activities, except for Playing games, than the reference group $(\mathrm{n}=1161)$. The greatest difference was found in searching for information. Analyses indicate that adolescents with intellectual disabilities are following a similar pattern of internet use as the reference group, but a digital lag is prevalent, and a more cognitively accessible web could be beneficial.
\end{abstract}


Keywords ( $\max 10)$ : accessibility; digital divide; digital inequality; digital participation; intellectual disability; internet use; online risks; questionnaire designs; survey method; youth.

\section{INTRODUCTION}

Internet accessibility is declared important for education, work, leisure and participation in society (Eurostat, 2018; UNICEF, 2017). Internet use is further considered an integrated part in everyday life activities also among children and adolescents (Livingstone et al., 2018). Daily use is reported in about $90 \%$ of young people both in Europe and in the USA ( Eurostat, 2017; PEW, 2018). In Sweden, where this study is conducted, $98 \%$ of 13 - to 18 -year-olds report using the internet daily as an integrated part of their everyday life (Swedish Media Council, 2017). Because of the internets' influence on education, work and leisure it is important to study internet use among all groups in society and, in particular in young people to gain knowledge on opportunities of internet use, and its possible risks (Livingstone et al., 2015; Livingstone et al., 2018). Until recently young people with disabilities were marginalized in research on internet use, as the research conducted focused on adults with disabilities (Söderström, 2013). However, it has been found that being digitally excluded affect the rights of adolescents with disabilities (Alper and Goggin, 2017). The importance of access to the internet for all is highlighted in the Convention on the Rights of Persons with Disabilities (UN, 2007) where it is expressed in Article 9: “...to take appropriate actions to promote access for persons with disabilities to new information and communications technologies and systems, including the Internet". Despite this the internet has not yet been made accessible to people with disabilities according to a survey study in Sweden and Great Britain (Helsper and Reisdorf, 2017), in which having a disability was found to be strongly related to internet non-use and more alarmingly to internet ex-use, as was societal factors of 
lower education, social isolation and unemployment. Disability is a complex phenomenon, reflecting the interaction between a person's abilities and features of the society in which he or she lives (WHO, 2019). Digital participation for individuals with disabilities differs with the complexity for persons with intellectual disability being highlighted (Alper and Goggin, 2017).

Existing surveys examining internet access and use often exclude persons with intellectual disabilities due to questions not being cognitively adapted. Therefore, knowledge about access to and use of the internet comparing adolescents with intellectual disabilities with young people without intellectual disabilities is limited (Chadwick et al., 2013; Chadwick et al., 2017). Intellectual disability is defined as difficulties in both intellectual and adaptive functioning prevalent in practical and social everyday life domains as well as in the conceptual domain (American Psychiatric Association, 2013). Difficulties in the conceptual domain for people with intellectual disabilities are with reasoning, knowledge and literacy: writing, reading, spelling in relation to the features of the surrounding environment (AAIDD, 2019; National Board of Health and Welfare, 2019). Variations of difficulties in everyday life are prevalent in different severity levels of intellectual disabilities called mild, moderate or severe intellectual disabilities (Kylén, 1997). The ability to function adaptively decreases with moderate or severe intellectual disabilities, compared to mild e.g. language skills decreases (American Psychiatric Association, 2013; Kylén 1997) which make internet use more complex. Although research is sparse it is shown that persons with intellectual disabilities can gain opportunities from using adapted computers to access the internet (Hoppestad, 2013). In a recent literature review by Lussier-Desrochers et al. (2017) five challenges to digital participation for persons with intellectual disabilities were identified: a) access to digital devices, b) sensorimotor skills to handle devices, c) cognitive abilities, d) technical requirements and e) comprehension of social codes and conventions when using internet. 
Access to internet-enabled devices has historically shown higher access to computers than mobile phones among people with intellectual disabilities: $50 \%$ have access to a computer and about $20 \%$ to a mobile phone (Palmer et al., 2012). However, the digital development is rapid and a recent study of adults with intellectual disabilities showed a higher possession of smartphones, $90 \%$, than computers, $61 \%$ (Chiner et al., 2017). The internet is used among people with intellectual disabilities for entertainment (Ramsten et al., 2018) and social contact, but challenges are reported with linguistic skills and handling personal settings for social media use (Shpigelman and Gill, 2014; Shpigelman, 2018). Further online risks for adolescents with intellectual disabilities have been identified in line with potential risks for young people in general, e.g. in contact with others (Seale and Chadwick, 2017). Several young people emphasize the risk of being bullied when using the internet but it is especially found among adolescents with intellectual disabilities (Alper and Goggin, 2017; Normand and Sallafranque-St-Louis, 2016). Research demonstrates that persons with intellectual disabilities are not unaware of different online risks (Bannon et al., 2015; Molin et al., 2015) although risks for vulnerable groups such as young people with intellectual disabilities need further investigation (Eurostat, 2017; Chadwick et al., 2017; Lough and Fisher, 2016). Comparative studies of internet use between people with intellectual disabilities and the general population are required to investigate digital participation and equalities and inequalities, e.g. regarding risks with the internet (Alper and Goggin, 2017; Chiner et al., 2017). To the authors' knowledge, there is only one comparative empirical study focusing on internet use of persons with and without intellectual disabilities (Jenaro et al., 2017). Data were collected using one-to-one interviews with adults with intellectual disabilities and online questionnaires for the convenience-sampled reference group. Results showed that $73 \%$ of adults with intellectual disabilities own a smartphone compared with $96 \%$ in the reference group. Further the results showed, that internet use by 
people with intellectual disabilities is more for recreational use e.g. gaming, and less for educational use, than in the reference group (Jenaro et al., 2017).

In summary, internet use is considered an integrated part of everyday life and vital for participation in society. Data on internet use among adolescents with intellectual disabilities have been requested and designing inclusive research methods suggested (Alper and Goggin, 2017).

In the present study a national survey was cognitively adapted so that adolescents with intellectual disabilities could provide data. This was important, as the voices of young people with intellectual disabilities is seldom heard in research (Chadwick and Fullwood, 2018). To gain in-depth knowledge on the equality or inequality in digital participation, comparative data from an age-appropriate reference group was used.

Thus, this study aims to investigate digital participation of adolescents with intellectual disabilities by comparing aspects of internet use among adolescents with and without intellectual disabilities. This study specifically addresses if there are differences between adolescents with intellectual disabilities in comparison to a reference group without intellectual disabilities regarding: i) access to internet-enabled devices ii) performing a variety of internet activities iii) difficulties in using the internet and iv) risks and risk management when using the internet.

\section{METHOD}

This study use a cross-sectional comparative design (Field, 2018) with a national survey distributed biannually named "Kids and Media" from the government agency the Swedish Media Council (2017) on the use of the internet and media among adolescents. It was adapted into an easy-read version for this study to enable participation of adolescents with intellectual disabilities. Comparative data for the reference group were obtained from the original national 
survey distributed to a randomised sample of adolescents aged 13-18 years (Swedish Media Council, 2017).

\section{Recruitment of participants}

Ethical approval was granted from the regional review board (Dnr 2014/370-31) and ethical principles were considered in all parts of the study. For recruitment of participants with intellectual disabilities, two provinces in Sweden were selected, one of them through convenience sampling as it was possible for the first author to visit special schools in that area, and the other because it was more densely populated than the first. In each province a stratified sample of two municipalities were selected based on high and low population densities and number of special-schools (National Agency for Education, 2016) as internet use may be affected by demographic characteristics (Swedish Media Council, 2015). The principals of all the eligible special schools were contacted in autumn 2016, and all accepted participation of their school/s $(n=1-3)$. Inclusion criteria for the study were: adolescents with intellectual disabilities, 13-20 years old, in the compulsory and upper-secondary special schools in the four municipalities. No exclusion criteria were used. The total selection of adolescents with intellectual disabilities in the special schools $(n=318)$ enabled inclusion of adolescents with different severity levels of intellectual disabilities because adolescents with mild intellectual disabilities are enrolled in different types of schools from adolescents with moderate or severe intellectual disabilities in Sweden. This inclusion was important since the digital participation is likely to vary among adolescents with intellectual disabilities. In summary, participants with different severity levels of intellectual disabilities, aged 13-20 years, attending 11 schools, five compulsory and six upper-secondary special schools, in four municipalities in two provinces in Sweden participated in the easy-read survey. 


\section{Data collection method}

Cognitive adaptations of the original survey "Kids and Media" (Swedish Media Council, 2017) were made in six steps, and resulted in an easy-read paper and web-based version. Steps were based on suggested research designs for persons with intellectual disabilities (Finlay and Lyons, 2001; Hartley and MacLean, 2006; Oschwald et al., 2014), the first and second authors' experience of the target group and results from a qualitative study that explored internet access and strategies to handle the digital environment (Alfredsson Ågren et al., 2018).

The original national survey consisted of 48 questions, most with sub-questions, generating 183 questions in total. In the first adaptive step, questions in the national survey that focused on abstract concepts were withdrawn in accordance with Finlay and Lyons (2001). Questions that were most relevant to retain from the original survey were selected in cooperation with the Swedish Media Council. The second step was to simplify the questions using easy-read text (Finlay \& Lyons, 2001). During the third step, the response scale was adapted to a one-word response on a 2-4-point Likert scale, as it has been shown that 5 points are understandable for persons with mild intellectual disabilities, but fewer are recommended (Hartley \& MacLean, 2006). Then, a web-based version was developed in cooperation with a technology company. The fourth step of adaptation used audio-assistance for questions and response alternatives, as suggested by Oschwald et al. (2014). In the fifth step two to four pictures were added per question, and one picture per response alternative, using Pictogrampictures (www.pictogram.se), for accessibility of adolescents with moderate intellectual disabilities (Hartley and MacLean, 2006). Finally, the sixth adaptation was to offer support, for those who needed it, from a person in the research team providing the participant with a tablet and giving support to $\log$ in to the survey. 
Pilot tests of the easy-read survey, both the paper and web-based versions, were conducted by the first author with one to five adolescents with intellectual disabilities using Think Aloud methodology (Patton, 2015). In these pilot tests the sixth adaptative step of a person supporting the adolescent to log in to the survey, if needed, was highly appreciated by the participants.

The easy-read survey includes four sections: a) demographics (6 questions), b) access to internet-enabled devices e.g. smartphones, tablets or computers, through ownership or sharing them with others ( 9 questions with 3 sub-questions), c) activities and internet activities including e.g. searching for information, using social media or gaming (19 questions) and d) questions on the adolescents' experiences of using the internet e.g. on difficulties using the internet (11 questions), giving 45 self-report questions, 3 with subquestions, generating a total of 54 questions. Of these, 29 questions were in accordance with the aim of this study and were therefore used in the present study. The easy-read survey was tested for internal consistency and reliability, giving an overall Cronbach's $\alpha=0.840$, indicating high internal consistency (Hinton et al., 2014).

\section{Procedure}

For the distribution of the easy-read survey, principals of the special schools and their administrative staff sent address lists of all pupils meeting inclusion criteria $(n=318)$ to the first author. The easy-read survey was posted in a survey package between November 2016 and September 2017, as address lists reached the first author. The survey package included an information letter for the caregiver/parent and one in easy-read text for the adolescent, together with a postal survey and log-in information with pictures for the web-based version, if they preferred to use that. It was sent out addressed to: "caregiver of [pupil's name]" to enable caregivers to give informed consent for the survey to be filled in. Two reminders 
containing the same package were sent out to participants who had not returned the survey at intervals of 2-4 weeks. Support from the first author was offered to access the survey during school-time. An information letter and consent form were distributed to and from caregivers/parents through the four schools that accepted this offer. The national survey "Kids and Media" was sent out to the reference group between August and December 2016 to a randomised sample of adolescents $(\mathrm{n}=3000)$, with four reminders (Swedish Media Council, 2017).

\section{Statistical data analysis}

Data were analysed using SPSS version 25 (IBM, 2017) with descriptive and comparative statistics using percentages and cross-tabulations. No question had more than nine missing values. For the statistical analysis, age, internet-activities and revealing personal information were dichotomised. For all the subsequent comparative analysis, chi-squared tests were used, and when necessary Fishers exact test was used (Field, 2018) as the variables were categorical with few categories. Statistical significance was set at $\mathrm{p}<0.05$.

\section{RESULTS}

\section{Demographics of the participating adolescents}

In total, 114 adolescents with intellectual disabilities participated in the easy read survey and a response rate of $36.2 \%$ was reached, which was equivalent to the reference group of $38.7 \%$ $(n=1161)$. Table 1 shows that participants with intellectual disabilities were older than the reference group and a higher proportion were male. A majority of adolescents with intellectual disabilities (75\%) stated they were accompanied when responding to the survey. 
An analysis of response bias based on school enrolment showed no difference between participants and non-responders.

Insert Table 1 about here

\section{Access to internet-enabled devices}

Table 2 shows significant differences between adolescents with intellectual disabilities and the reference group in access to all internet-enabled devices. A lower proportion of adolescents with intellectual disabilities had access to smartphones (67\% vs. $98 \%)$ and computers of their own (54\% vs. $77 \%)$. In addition, Table 2 shows that a higher proportion of adolescents with intellectual disabilities had no access to devices at all. However, more adolescents with intellectual disabilities had a tablet of their own (61\% vs. $48 \%)$ while the reference group more often shared tablets.

Overall, smartphones were the internet-enabled device that most participants had one of their own of in both groups. At the same time, this was the device that showed the largest difference in proportions between the groups, with two-thirds of adolescents with intellectual disabilities compared to nearly all of the reference group having one of their own $(p<0.001)$.

\section{Insert Table 2 about here}

\section{Internet activities performed}

It is displayed in Table 3 that adolescents with intellectual disabilities are less active on the internet than the reference group. There are significant differences for most internet activities, with adolescents with intellectual disabilities more likely to not perform them at all compared with the reference group. An exception is Play games which is performed by more 
adolescents with intellectual disabilities $(84 \%)$ than the reference group $(63 \%)(p<0.001)$. Besides Play games, the internet activities performed by most in both groups are the same: Watch film clips (on YouTube), which 78\% with intellectual disabilities do vs. $97 \%$ in the reference group, and Listen to music, which $76 \%$ with intellectual disabilities do compared to $93 \%$ in the reference group $(\mathrm{p}<0.001)$. About half of the adolescents with intellectual disabilities Have contact with friends on social media compared to $93 \%$ in the reference group $(\mathrm{p}<0.001)$. The internet activity that displayed the largest difference in proportions between the groups was Search for new knowledge/ information, with $20 \%$ of adolescents with intellectual disabilities searching the internet compared to $86 \%$ in the reference group.

\section{Insert Table 3 about here}

\section{Difficulties using the internet}

Results displayed in Table 4 show a significantly higher degree of difficulties for adolescents with intellectual disabilities compared with the reference group to Send text-based messages such as e-mails and Find and Understand information on the internet $(\mathrm{p}<0.001)$. Among adolescents with intellectual disabilities between $20-30 \%$ more state they never do any of the activities compared with the reference group where nearly none state they never do them. Furthermore, adolescents with intellectual disabilities were more likely to respond that the difficulty they perceive "Varies"; compared to the reference group; e.g. Understand information (34\% vs. 10\%) (see Table 4).

Insert Table 4 about here 


\section{Risks and risk management when using the internet}

A significantly higher proportion of adolescents with intellectual disabilities have experiences of being bullied on the internet than adolescents in the reference group: $23 \% \mathrm{vs.} 11 \%$ $(p<0.001)$. Table 5 shows that a significantly lower proportion of adolescents with intellectual disabilities take risks in revealing personal information online compared to the reference group; e.g., gives one's real name (48\% vs. $76 \%$, $\mathrm{p}<0.001)$.

\section{Insert Table 5 about here}

Managing the risks through talking daily or weekly with an adult about things seen on the internet was significantly less common among adolescents with intellectual disabilities $(24 \%)$ than in the reference group $(57 \%)(\mathrm{p}<0.001)$. Talking to an adult about games played, were done by $21 \%$ of adolescents with intellectual disabilities compared to $36 \%$ in the reference group $(\mathrm{p}<0.001)$.

\section{DISCUSSION}

This study, designed to investigate digital participation by comparing aspects of internet use, including access, use, difficulties, and risks and risk management, among adolescents with intellectual disabilities in comparison with an age-appropriate reference group, is, to our knowledge, the only study to give a comprehensive depiction of internet use and digital participation for this target group.

The requirements for digital participation, summarized as five challenges or dimensions interacting with each other, the person and the environment, identified by Lussier-Desrochers et al. (2017) and described earlier, are all to different extent addressed in this study. Initially 
the dimension of access to digital devices is a necessity to access internet and its content. The results of the present study show that adolescents with intellectual disabilities had less access to internet-enabled devices than the reference group, which is in line with the results in earlier research (Jenaro et al., 2017; Palmer et al., 2012). Smartphones were the device that the greatest proportion of adolescents with intellectual disabilities had access to, $67 \%$, though within the reference group nearly all (98\%) had access to smartphones. Overall, over $60 \%$ of participants with intellectual disabilities had access to internet-enabled devices by owning or sharing them and tablets were owned by a higher proportion of adolescents with intellectual disabilities than the reference group. It can thus be suggested that the dimension of access to devices (Lussier -Desrochers, 2017) is a challenge to some of the participants in this study but not to a majority of them. Tablets have been explained as easy to handle cognitively, with a simple interface and access to programs through picture-based applications on the start screen (Alfredsson Ågren et al., 2018; Hoppestad, 2013; Palmer et al., 2012). Compared to smartphones, tablets offer a bigger screen for easier sensorimotor handling (LussierDesrochers et al., 2017). This shows that the second and third challenges towards digital participation, described as cognitive abilities and sensorimotor skills (Lussier-Desrochers et al., 2017), were also addressed in the present study by the higher use of internet-enabled devices that facilitated the performance of internet activities. By the continuous development of adaptive hardware and software devices, there should be opportunities to increase the access to internet-enabled devices for people with different severity levels of intellectual disabilities (Hoppestad, 2013).

Despite that $60 \%$ had access to internet-enabled devices, significantly fewer adolescents with intellectual disabilities performed most of the internet activities compared with the reference group. One possible explanation of this may be a combination of cognitive challenges and technical requirements as described by Lussier-Desrochers (2017) as the skills 
to keep the internet enabled devices in working conditions and possible to connect to internet. To access the content on internet is more complex in relation to having mere access to the devices. The greatest difference between the groups in their internet activities was found for Search for new knowledge/information: $20 \%$ of adolescents with intellectual disabilities performed searches, compared to $86 \%$ in the reference group. The low percentage found for Searching for new knowledge/ information may be explained by the requirement of higher cognitive skills as it involves several tasks to get to the endpoint, as well as linguistic skills, which are both challenges for people with intellectual disabilities ( Alfredsson Ågren et al, 2018; Lussier-Desrochers et al, 2017; Molin et al., 2015). The difference in digital participation found between adolescents with intellectual disabilities and the reference group in Searching for new knowledge and information is critical because gaining information has been identified as a first step towards participation for adolescents in general, and particularly for persons with intellectual disabilities, to enable decision-making and engage in activities (Goodman et al., 2008). This can be viewed as an example of difficulties to act out the rights of the adolescents to become participatory citizens in this digital age (Alper and Goggin, 2017). Results further demonstrated that difficulties in Finding and Understanding information on the internet as well as Sending text-based messages varied for adolescents with intellectual disabilities compared to the reference group. It can be argued that adolescents with intellectual disabilities participate in these activities to some extent but have problems with technical requirements e.g. with web-accessibility navigating the web, and therefore could need more technical support or a more accessibly designed web to find suitable information.

Nevertheless, a high proportion of adolescents both with and without intellectual disabilities performed the internet activities Watch film clips (on YouTube) 78\% vs. 97\% and 
Listen to music $76 \%$ vs. $93 \%$, and this result is concordant with other studies (Jenaro et al., 2017; Livingstone et al., 2015). Among adolescents in general, recreational activities such as watching film clips have been increasing in recent years, and nearly all adolescents do this (Ní Bhroin, 2018). This result can be an indication of adolescents with intellectual disabilities digitally participating in the same internet activities as adolescents in the general population and that the digital environment in this specific area were designed with both technical support and solutions for cognitive limitations in place, for a majority of participants. Internet activities for entertainment have been highlighted as one of the main activities on the internet for persons with intellectual disabilities (Ramsten et al., 2018; Sallafranque-St-Louis and Normand, 2017). These internet activities are picture- and audio-based rather than text-based, which is less cognitively demanding for people with intellectual disabilities (Alfredsson Ågren et al., 2018). Based on these results, a recommendation is to use picture- and audiobased rather than text-based services to make the internet accessible for persons with intellectual disability. This in turn may increase opportunities for individuals with different severity levels of intellectual disabilities to use the internet.

The internet activity Play games was the only internet activity performed by a higher proportion of adolescents with intellectual disabilities compared to the reference group (84\% vs. $63 \%$ ). This is intriguing because Play games indicates a more interactive use of the device including challenges in both the technical and cognitive dimension (Lussier-Desrocher et al, 2017). There are games available on the market at many different levels of difficulty, and Play games has been identified in research including young adults with intellectual disabilities as a solitary internet activity, performed for solitary pastime, not necessarily including interactions with others (Ramsten et al., 2018). Further, the high percentage of adolescents with intellectual disabilities having a tablet of their own may contribute to these proportions 
as tablets have picture-based applications and bigger screens useful when playing games (Alfredsson Ågren et al, 2018).

About half of the adolescents with intellectual disabilities (52\%) Have contact with friends on social media, compared to almost all in the reference group (93\%). Using social media requires high-level linguistic skills (Lussier-Desrochers et al, 2017) and access to an appropriate internet-enabled device, e.g. a smartphone (Caton and Chapman, 2016). Previous research on people with intellectual disabilities shows limited social networks in general (van Asselt-Goverts et al., 2015) and studies on internet use and social networks among people with intellectual disabilities show the same pattern (Chadwick and Fullwood, 2018; Sallafranque-St-Louis and Normand, 2017). At the same time, the internet has been put forward as generating opportunities for contact with friends through social media, if the right support is offered (Shpigelman and Gill, 2014; Raghavendra, Hutchinson, Grace, Wood, \& Newman, 2018). As about 50\% have contact with friends on social media, the result indicates that internet could be one way of interacting with others and building friendships. The result that equal numbers of participants with and without intellectual disabilities use Phone videocalls shows that this is another opportunity, other than social media, for contacting friends. Having social relationships is a well-studied and important aspect of wellbeing and health and should be enabled among the target group (van Asselt-Goverts et al., 2015).

However, results also demonstrated that twice as many participants with intellectual disabilities reported being bullied on the internet compared to the reference group. This is in accordance with other research showing a high risk of online bullying of people with intellectual disabilities (Alper and Goggin, 2017; Jenaro et al., 2018; Normand and Sallafranque-St-Louis, 2016) and can be related to the fifth challenge for digital participation; the dimension of comprehension of social codes and conventions when using the internet 
(Lussier-Desrochers et al, 2017). Understanding a social code requires cognitive abilities since this is an abstract phenomenon. When it comes to managing risks, the result shows that adolescents with intellectual disabilities seem to be more reluctant than the reference group to reveal personal information on the internet, e.g. their names. This finding was somewhat unexpected and contradicts other research where the risk of providing too much personal information was reported as one of the greatest risks for persons with intellectual disabilities using the internet, (Chadwick et al., 2017). This may indicate that the dimension of codes and conventions were less of a challenge for the participants in this study. However, it may also indicate that the content accessed on internet by the participants through the internet activities performed differed between the groups and that a lower proportion of adolescents with intellectual disabilities did less of internet activities where this was an issue, such as having contact with friends on social media. However, playing games is an internet activity where the revealing of personal information is of relevance and a high proportion of adolescents with intellectual disabilities, $84 \%$, performed this internet activity.

Overall, the results of this study are both in agreement with and contradict earlier results concerning the proportion of young people with intellectual disabilities playing online games and having access to smartphones. Playing online games has been found in other studies among only $48 \%$ (Chiner et al., 2017) and 37\% of participants with intellectual disabilities (Jenaro et al., 2017). This study indicates that Swedish adolescents both with and without intellectual disabilities Play games to a high extent (83\% vs. 63\%), that in turn might be related to societal and economic circumstances such as high access to internet connections at home and personal internet enabled devices. Concerning access to smartphones the present study found that $67 \%$ of the participants with intellectual disabilities had access to smartphones. These numbers are contrary to the ones in the study from Palmer (2012), where 
only $20 \%$ of participants with intellectual disabilities had access to mobile phones, but equivalent to more recent research from Spain (Jenaro et al., 2017) with 73\% participants with intellectual disabilities having access to smartphones. This is an example of the vast development of internet-enabled devices and its accessibility even to young people with intellectual disabilities in the five years separating the two studies.

\section{Methodological considerations}

While the results show an important insight in digital participation for adolescents with intellectual disabilities in comparison with adolescents in the general population there are some methodological considerations to address. The strengths of this study were the selection process of provinces and the stratified sample of municipalities, both rural and urban. This increased the generalisability of results as did the participation of all eligible special schools in these municipalities, leading to a total selection of adolescents with intellectual disabilities, aged 13-20. On the other side the comparative data obtained from the Swedish Media Council used a randomised sample and, in this study, we used a stratified sample with unequally large groups resulting in limitations for the generalisability. The national survey from the Swedish media council (2017) did not include questions on the importance of doing the internet activities. Future studies are suggested to include questions on the value and meaning of performing internet activities since this probably influence if and how often the activities will be performed. Adolescents were urged to respond to the survey themselves; however, results show that a majority of participants with intellectual disabilities answered the easy-read survey with someone else. The involvement of a supporting person among the participants can be considered a bias that cannot be controlled for and may have affected the answers; e.g. by answering that fewer risks were taken. The first author as supporting person only gave 
support on technical matters and did not interfere in the actual answering of the survey and that might have been the case for other support persons as well. Non-response analysis showed no differences between responders and non-responders regarding levels of severity of intellectual disabilities. This, together with high internal consistency $(\alpha=0.864)$ supports the relevance of the adaptations made. The response rate of $36.6 \%$ is about $10 \%$ higher than in previous studies ( Chiner et al., 2017; Palmer et al., 2012) and is concordant with the reference group in this study (Swedish Media Council, 2017). Considering that young people with intellectual disabilities seldom have been included in surveys the similarities in response rate is promising for future research including people with intellectual disabilities. The sample showed significant differences in sex and age compared to the reference group. This is in line with statistics on adolescents with intellectual disabilities in schools in Sweden, as a higher percentage of pupils in special schools are male, about $60 \%$, and adolescents are in school longer when enrolled in special school (National Agency for Education, 2016). This may have had an impact on the results on content accessed by the participants in the study.

\section{Concluding remarks}

This study indicates that internet use is a part of everyday life for adolescents with intellectual disabilities. About $70-80 \%$ of adolescents with intellectual disabilities have access to internetenabled devices and many are using the internet, though possibly with challenges that are both cognitive and technical, but also with an awareness of the risks using the internet.

Nevertheless, access to internet-enabled devices is lower for adolescents with intellectual disabilities than without intellectual disabilities, except in tablets. Further, a lower proportion of adolescents with intellectual disabilities do fewer internet activities than in the reference group, except for playing games. The greatest differences in internet activities was in searching for information that only $20 \%$ of the adolescents with intellectual disabilities 
reported compared to $86 \%$ in the reference group. The difficulties in sending text-based messages, finding and mostly understanding information on the internet "Varies" for a higher proportion of adolescents with intellectual disabilities than the reference group indicating an experience in doing these activities but not always succeeding in performing them suggesting an inaccessible digital environment. Overall the results indicate that adolescents with intellectual disabilities are following a similar pattern of internet use as the reference group, but a digital lag is evident. Digital accessibility may be a way to participate in everyday life decisions and to increase opportunities to be a member of society on equal terms with others, in accordance with the Convention on the Rights of Persons with Disabilities (CRPD) (UN, 2007). Implications of these results are the need to enable digital inclusion and participation in internet activities for adolescents with intellectual disabilities. To overcome the digital lag and increase the proportion of people with intellectual disabilities Searching for new

knowledge/information on internet in combination with decreasing the difficulties reported in Finding and Understanding information in this study the European guidelines for website accessibility, Web Content Accessibility Guidelines (WCAG) should be addressed (EU, 2016), in which the importance of cognitive accessibility has recently been highlighted. When implementing these guidelines it is crucial to consider technical requirements to become simple and intuitive and websites must be robust and possible to perceive, handle and understand in order to be more accessible, in particular for persons with disabilities (SFS, 2018). It is crucial in a digitalised society to conduct accessibility analyses of websites and digital services using cognitive accessibility criteria to ensure that these services can be used by everyone in the population, recognising that accessibility includes more than physical and social accessibility. This broad perspective on accessibility can enable digital participation and prevent further exclusion, not only from engaging in internet activities, but overall in everyday life and society. 


\section{Acknowledgements}

The authors thank the Swedish Media Council for the significant cooperation and sharing of comparative data that made this study possible. Thanks also to the principals and teachers in the participating special schools for accommodating the data collection, and all the participants.

\section{Funding}

This work was supported by Linköping University, Sweden; The Foundation Solstickan, Stockholm, Sweden and The Swedish Association of Occupational Therapy, Stockholm, Sweden.

\section{Conflict of Interest}

The Authors declare that there is no conflict of interest.

\section{References}

AAIDD. American Association on Intellectual and Developmental Disabilities (2019) Available at: https://aaidd.org/intellectual-disability/definition (accessed May 21st 2019).

Alfredsson Ågren K, Kjellberg A and Hemmingsson H (2018) Access to and use of the internet among adolescents and young adults with intellectual disabilities in everyday settings. Journal of Intellectual and Developmental Disability

DOI:https://www.tandfonline.com/doi/full/10.3109/13668250.2018.1518898 
Alper M and Goggin G (2017) Digital technology and rights in the lives of children with disabilities. New Media and Society 19 (5):726-740.

American Psychiatric Association (2013) Diagnostic and statistical manual of mental disorders (DSM-5®): American Psychiatric Pub.

Bannon S, McGlynn T, McKenzie K, et al (2015) The positive role of Internet use for young people with additional support needs: Identity and connectedness. Computers in Human Behavior 53: 504-514.

Caton S and Chapman M (2016) The use of social media and people with intellectual disability: A systematic review and thematic analysis. Journal of Intellectual and Developmental Disability 41: $125-139$.

Chadwick D and Fullwood C (2018) An Online Life Like Any Other: Identity, Self-Determination, and Social Networking among Adults with Intellectual Disabilities. Cyberpsychology, Behavior, and Social Networking 21: 56-64.

Chadwick D, Quinn S and Fullwood C (2017) Perceptions of the Risks and Benefits of Internet Access and Use by People with Intellectual Disabilities. British Journal of Learning Disabilities 45: 21-31.

Chadwick D, Wesson C and Fullwood C (2013) Internet Access by People with Intellectual Disabilities: Inequalities and Opportunities. Future Internet 5: 376.

Chiner E, Gómez-Puerta M and Cardona-Moltó MC (2017) Internet use, risks and online behaviour: The view of internet users with intellectual disabilities and their caregivers. British Journal of Learning Disabilities 45: 190-197.

EU. European Union (2016) Accessibility of the websites and mobile applications of public sector bodies. Directive (EU) 2016/2102 of the European Parliament and of the Council Available at: https://eur-lex.europa.eu/legal-content/EN/TXT/?uri=CELEX\%3A32016L2102

Eurostat. (2017) Being Young in Europe today - Digital world. Available at: https://ec.europa.eu/eurostat/statisticsexplained/index.php?title=Being_young_in_Europe_today_- 
Alfredsson Ågren, Kjellberg \& Hemmingsson

Digital participation? Internet use among adolescents with and without intellectual disabilities: A comparative study

_digital_world\#Conclusions:_what_future_for_young_people_in_the_digital_world.3F (accessed 21 May 2019)

Eurostat. (2018) Internet access and use statistics households and individuals. Available at: https://ec.europa.eu/eurostat/statisticsexplained/index.php?title=Archive:Internet_access_and_use_statistics__households_and_individuals\&oldid=379591 (accessed at 20 May 2019)

Field AP. (2018) Discovering statistics using IBM SPSS statistics: 5. ed. Sage publications.

Finlay WML and Lyons E (2001) Methodological issues in interviewing and using self-report questionnaires with people with mental retardation. Psychological Assessment 13: 319-335.

Goodman J, Hurst J and Locke C (2008) Occupational therapy for people with learning disabilities : a practical guide: Edinburgh : Churchill Livingstone.

Hartley SL and MacLean WE Jr (2006) A review of the reliability and validity of Likert-type scales for people with intellectual disability. Journal Of Intellectual Disability Research: 50: 813827.

Helsper EJ and Reisdorf BC (2017) The emergence of a "digital underclass" in Great Britain and Sweden: Changing reasons for digital exclusion. New Media and Society 19 (8):1253-1270. Hinton PR, McMurray I and Brownlow C. (2014) SPSS explained: Hove : Routledge, 2014. 2nd edition.

Hoppestad BS. (2013) Current perspective regarding adults with intellectual and developmental disabilities accessing computer technology. Disability \& Rehabilitation: Assistive Technology. $8(3): 190-194$.

IBM (2017) IBM SPSS Statistics for Windows, Version 25.0.: Armonk, NY: IBM Corp.

Jenaro C, Flores N, Cruz M, et al. (2017) Internet and cell phone usage patterns among young adults with intellectual disabilities. Journal of Applied Research in Intellectual Disabilities 2018(31): 259-272. 
Jenaro C, Flores N, Vega V, et al. (2018) Cyberbullying among adults with intellectual disabilities: Some preliminary data. Research in Developmental Disabilities 72: 265-274.

Kylen,G. (1997) Begåvning och begåvningshandikapp. [The intellect and intellectual handicaps]. Stockholm: Stiftelsen ALA, Hnadikappinstitutet. In Swedish.

Livingstone S, Cagiltay K and Ólafsson K (2015) EU Kids Online II Dataset: A cross-national study of children's use of the Internet and its associated opportunities and risks. British Journal of Educational Technology 46: 988-992.

Livingstone S, Mascheroni G and Staksrud E (2018) European research on children's internet use: Assessing the past and anticipating the future. New Media \& Society 20(3): 1103-1122. Lough E and Fisher MH. (2016) Internet use and online safety in adults with Williams syndrome. Journal of Intellectual Disability Research 60: 1020-1030.

Lussier-Desrochers D, Normand CL, Romero-Torres A et al. (2017) Bridging the digital divide for people with intellectual disability. Cyberpsychology 11: 53-72.

Molin M, Sorbring E and Löfgren-Mårtenson L (2015) Teachers' and parents' views on the Internet and social media usage by pupils with intellectual disabilities. Journal of Intellectual Disabilities 19: 22-33.

National Board of Health and Welfare (2019) Disability [In Swedish]. Available at: https://www.socialstyrelsen.se/en/ (Accessed 30 July 2019)

National Agency for Education (2016) Statistics on schools in Sweden. [In Swedish]. Available at: https:/www.skolverket.se/skolutveckling/statistik/sok-statistik-om-forskola-skola-ochvuxenutbildning (Accessed 19 Sept 2016).

Ní Bhroin N and Rehder MM (2018) Digital Natives or Naïve Experts? Exploring how Norwegian children (aged 9-15) understand the Internet. EU Kids Online. Avaliable at: http://www.lse.ac.uk/media-and-communications/research/research-projects/eu-kidsonline/news Accessed 10 Feb 2019. 
Normand CL and Sallafranque-St-Louis F (2016) Cybervictimization of Young People With an Intellectual or Developmental Disability: Risks Specific to Sexual Solicitation. Journal of Applied Research in Intellectual Disabilities 29: 99-110.

Oschwald M, Leotti S, Raymaker D, et al. (2014) Development of an audio-computer assisted selfinterview to investigate violence and health in the lives of adults with developmental disabilities. Disability and Health Journal 7: 292-301.

Palmer SB, Wehmeyer ML, Davies DK, et al (2012) Family members' reports of the technology use of family members with intellectual and developmental disabilities. Journal of Intellectual Disabilities Resarch 56: 402-414.

Patton MQ. (2015) Qualitative research \& evaluation methods : integrating theory and practice : the definitive text of qualitative inquiry frameworks and options. 4. ed.Thousand Oaks, California: SAGE Publications, Inc.

PEW (2018) Teens, Social media and Technology 2018. Available at: https://www.pewinternet.org/2018/05/31/teens-social-media-technology-2018/ Accessed 10 May 2019.

Raghavendra, P., Hutchinson, C., Grace, E., Wood, D., \& Newman, L. (2018). "I like talking to people on the computer": Outcomes of a home based intervention to develop social media skills in youth with disabilities living in rural communities. Research in Developmental Disabiblities 76: 110-123.

Ramsten C, Martin L, Dag M, et al. (2018) Information and communication technology use in daily life among young adults with mild-to-moderate intellectual disability. Journal of Intellectual Disabilities: DOI: 10.1177/1744629518784351.

Sallafranque-St-Louis F and Normand CL (2017) From solitude to solicitation: How people with intellectual disability or autism spectrum disorder use the internet. Cyberpsychology 11: 7996.

Seale J and Chadwick D. (2017) How does risk mediate the ability of adolescents and adults with intellectual and developmental disabilities to live a normal life by using the Internet? Cyberpsychology 11: 110-126. 
SFS (2018) SFS 2018:1937. The Act on Accessability to Digital Public Services [In Swedish]. In: Finances Do (ed). Stockholm.

Shpigelman C-N (2018) Leveraging Social Capital of Individuals with Intellectual Disabilities through Participation on Facebook. Journal Of Applied Research In Intellectual Disabilities 31: e79e91.

Shpigelman CN and Gill CJ (2014) How do adults with intellectual disabilities use Facebook? Disability \& Society 29: 1601-1616.

Swedish Media Council (2015) Kids and Media [In Swedish: Ungar och medier: Fakta om barns och ungas användning och upplevelser av medier]. Kultur och utbildningsdepartementet. Stockholm. Available at: https://statensmedierad.se/ovrigt/inenglish.579.html.

Swedish Media Council (2017) Kids and Media [In Swedish: Ungar och Media. Fakta om barns och ungas användning och upplevelser av medier].

Söderström, S. (2013) Digital Differentiation in Young People's Internet Use-Eliminating or Reproducing Disability Stereotypes. Future Internet , 5, 190-204; doi:10.3390/fi5020190

UN, United Nations (2007) Convention on the Rights of Persons with Disabilities. New York:UN. Available at: https://www.un.org/development/desa/disabilities/convention-on-the-rights-ofpersons-with-disabilities.html (accessed 21 May 2019)

UNICEF (2017) The State of the Worlds Children 2017. Children in a Digital world. In: Division of Communication U (ed). Available at: https://www.unicef.org/publications/index_101992.html (Accessed 10 May 2019)

Van Asselt-Goverts AE, Embregts PJCM, Hendriks AHC, et al. (2015) Do social networks differ? Comparison of the social networks of people with intellectual disabilities, people with autism spectrum disorders and other people living in the community. Journal of Autism and Developmental Disorders 45: 1191-1203.

WHO, World Health Organisation (2019) Health topics, Disabilities. Available at: https://www.who.int/topics/disabilities/en/ (accessed 30 July 2019). 


\section{Tables}

Table 1. Demographic data for adolescents with intellectual disabilities and the reference group.

\begin{tabular}{|c|c|c|c|}
\hline & $\begin{array}{l}\text { Adolescents with } \\
\text { intellectual disabilities } \\
(\mathbf{n}=114) \\
\text { n (\%) }\end{array}$ & $\begin{array}{l}\text { Reference } \\
\text { group } \\
(\mathrm{n}=1161) \\
\text { n (\%) }\end{array}$ & $\begin{array}{l}\text { p-value } \\
\leq\end{array}$ \\
\hline Sex & & & 0.005 \\
\hline Boys & $67(59)$ & $517(45)$ & \\
\hline Girls & $47(41)$ & $632(55)$ & \\
\hline Age (years) & & & 0.001 \\
\hline $13-16$ years & $60(53)$ & $815(71)$ & \\
\hline $17-20$ years & $54(47)$ & $339(29)$ & \\
\hline Living with both parents & & & 0.849 \\
\hline Yes & $75(67)$ & $806(69)$ & \\
\hline No & $36(32)$ & $341(30)$ & \\
\hline Living on their own & $1(1)$ & $14(1)$ & \\
\hline Siblings & & & 0.394 \\
\hline Yes & $103(91)$ & $1083(93)$ & \\
\hline No & $10(9)$ & $78(7)$ & \\
\hline
\end{tabular}

Bold indicates statistical significance. 
Table 2. Access to internet-enabled devices among adolescents with intellectual disabilities in comparison with the reference group.

\begin{tabular}{|c|c|c|c|}
\hline Access to internet-enabled devices & $\begin{array}{l}\text { Adolescents with } \\
\text { intellectual disabilities } \\
(\mathrm{n}=114) \\
\%\end{array}$ & $\begin{array}{l}\text { Reference } \\
\text { group } \\
(n=1161) \\
\%\end{array}$ & $\begin{array}{l}p \text {-value } \\
\leq\end{array}$ \\
\hline Smartphone & & & 0.001 \\
\hline -has own & 67 & 98 & \\
\hline -shares & 3 & 1 & \\
\hline -does not have & 30 & 1 & \\
\hline Tablet & & & 0.013 \\
\hline -has own & 61 & 48 & \\
\hline -shares & 20 & 33 & \\
\hline -does not have & 19 & 19 & \\
\hline Computer & & & 0.001 \\
\hline -has own & 54 & 77 & \\
\hline -shares & 25 & 21 & \\
\hline -does not have & 21 & 2 & \\
\hline Smart tv & & & 0.001 \\
\hline -has own & 44 & 39 & \\
\hline -shares & 48 & 59 & \\
\hline -does not have & 8 & 2 & \\
\hline Gaming console & & & 0.001 \\
\hline -has own & 38 & 35 & \\
\hline -shares & 25 & 47 & \\
\hline -does not have & 37 & 18 & \\
\hline
\end{tabular}


Table 3. Internet activities performed among adolescents with intellectual disabilities in comparison with the reference group.

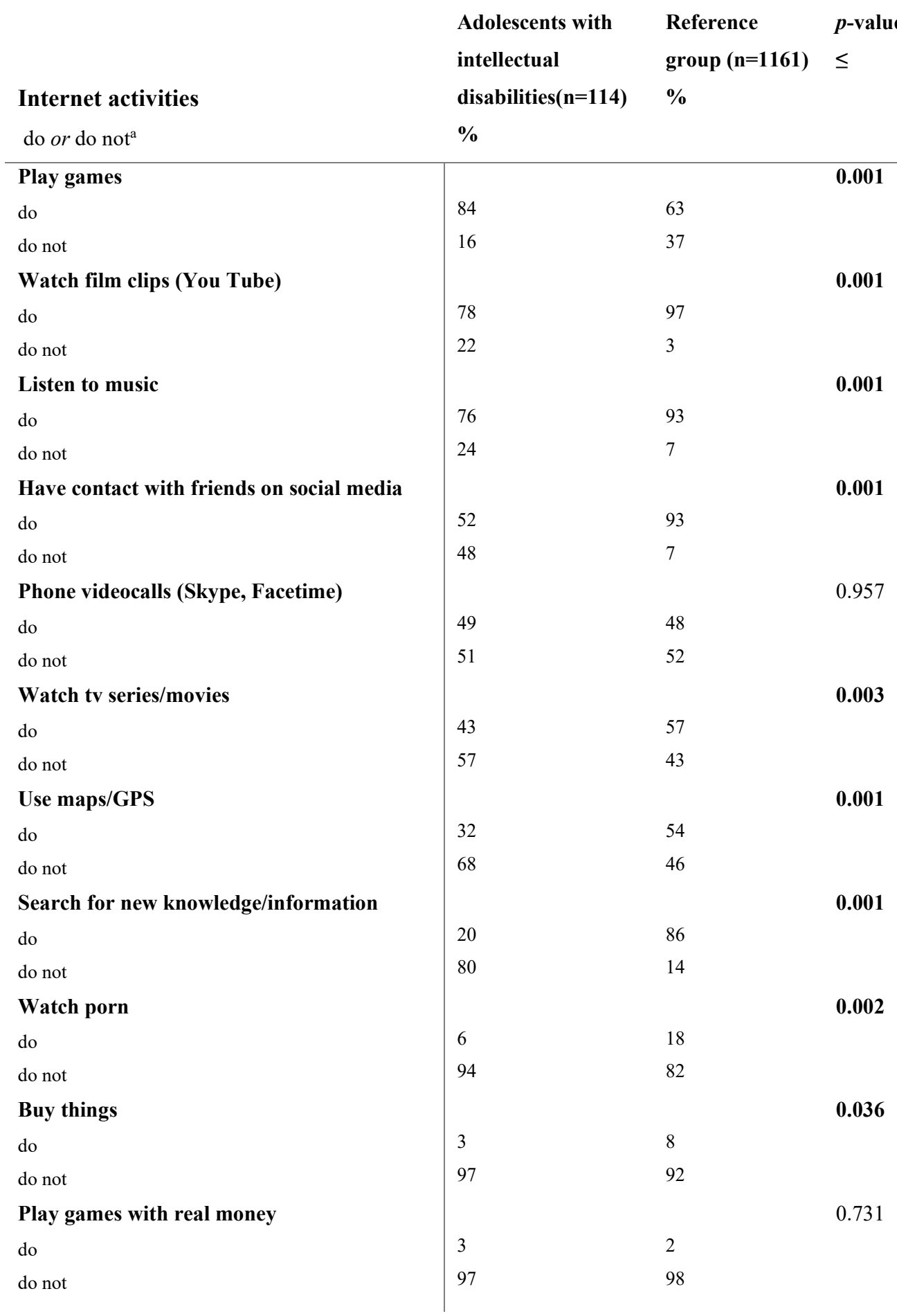

${ }^{a}$ The four internet-activities: Play games, Have contact with friends on social media, Phone videocalls (Skype, Facetime) and Use maps/GPS only had the two response alternatives; do or do not. The seven others had four response alternatives being do daily/weekly/rarely/never and where thereby dichotomised into two; do (daily/weekly) - do not (rarely/never). Bold indicates statistical significance. 
Table 4. Difficulties using the internet among adolescents with intellectual disabilities in comparison with the reference group.

\begin{tabular}{l|lll} 
& $\begin{array}{l}\text { Adolescents with } \\
\text { intellectual disabilities } \\
(\mathbf{n = 1 1 4})\end{array}$ & $\begin{array}{l}\text { Reference } \\
\text { group } \\
(\mathbf{n}=\mathbf{1 1 6 1 )}\end{array}$ & $\begin{array}{l}\boldsymbol{p} \text {-value } \\
<\end{array}$ \\
Difficulties using the internet to: & $\%$ & $\%$ & $\mathbf{0 . 0 0 1}$ \\
\hline Send text-based messages & 34 & 1 & \\
Never do & 11 & 4 & \\
Difficult & 21 & 12 & $\mathbf{0 . 0 0 1}$ \\
Varies & 34 & 83 & \\
Easy & & & \\
Find information on the internet & 24 & 1 & \\
Never do & 8 & 2 & \\
Difficult & 31 & 7 & \\
Varies & 37 & 90 & \\
Easy & & & \\
Understand information on the internet & 21 & 0.5 & \\
Never do & 24 & 3 & \\
Difficult & 34 & 86.5 & \\
Varies & 21 & &
\end{tabular}

Bold indicates statistical significance. 
Table 5. 'Risks taken in revealing personal information when using the internet' for adolescents with intellectual disabilities in comparison with the reference group.

\begin{tabular}{l|lll} 
& Adolescents with & Reference group & $p$-value \\
Risks taken in revealing personal & intellectual disabilities & $(\mathbf{n}=\mathbf{1 1 6 1})$ & $<$ \\
information using the internet & $\%$ & $\%$ & $\mathbf{0 . 0 0 1}$ \\
\hline Gives one's real name & 48 & 76 & $\mathbf{0 . 0 0 1}$ \\
Posts photos of oneself & 44 & 90 & $\mathbf{0 . 0 0 1}$ \\
Gives the name of the school one & 31 & 52 & \\
attends & & &
\end{tabular}

